\title{
Ritter Syndrome Mimicking Drug Eruption
}

\section{Kadir İDIN, Seniyye Ülgen ZENGIN, Harun UYSAL, Selçuk ALVER, Ziya SALIHOĞLU}

\section{Department of Anaesthesiology and Reanimation, Bezmialem Vakif University Faculty of Medicine, Istanbul, Turkey}

\section{ABSTRACT}

Ritter syndrome mimicking drug eruption staphylococcal scalded skin syndrome is a rare fatal condition in adults with erythematous and bullous lesions. With appropriate and immediate therapy, mortality decreases by 5\%; a differential diagnosis is necessary. In this case, we report Ritter syndrome mimicking drug eruption.

Keywords: Staphylococcal scalded skin syndrome, Ritter syndrome, intensive care

\section{Introduction}

Staphylococcal scalded skin syndrome (SSSS), also known as Ritter syndrome, generally occurs because of staphylococcal exfoliative toxins. It is mostly encountered in the maternity and pediatrics wards, but rarely seen in adults. It is characterized by fever, generalized erythema, and flaccid bullae with positive Nikolsky's sign that are rapidly ruptured and leave large lesions (1). This disease displays a fatal progress with diffuse skin barrier loss, dehydration, hypoproteinemia, hypothermia, and secondarily developed gram-negative infections (often pseudomonas-origin) (1-3).

\section{Case Presentation}

A 70-year-old patient with the diagnosis of prostate cancer was hospitalized in the clinic of internal diseases in a private hospital because of the development of pneumonia. Because respiratory and cardiac arrest developed on the $1^{\text {st }}$ day of hospitalization, orotracheal intubation was performed and cardiopulmonary resuscitation (CPR) procedure was initiated. The patient who responded to CPR with ventricular tachycardia in the $5^{\text {th }}$ minute was admitted to the intensive care unit. Then, dopamine infusion was administered to the patient. The urinary cultures of the patient with intermittent fever had revealed the growth of Candida albicans at the time of admission to the intensive care unit and the growth of Acinetobacter baumannii on the $16^{\text {th }}$ day. Colimycin $(150 \mathrm{mg}, 1 \times 1)$ was administered to the patient. On the $19^{\text {th }}$ day of hospitalization, skin eruption occurred on the front of the body, and pheniramine maleate ampule and cream was applied for the allergic reaction to medications. The patient was admitted to the intensive care unit of our hospital on the $21^{\text {st }}$ day of hospitalization in the private hospital. When the patient was admitted to our unit, his arterial pressure was $95-58 \mathrm{mmHg}$, pulse was 101 beats $/ \mathrm{min}$, fever was $36.6^{\circ} \mathrm{C}$, and central venous pressure was $9 \mathrm{mmHg}$. His cultures were taken. Red bullous lesions were observed on the front and back surfaces of the upper body, interior surfaces of the arms (expanding towards the armpits), and interior surfaces of the legs. Moreover, there were skin eruptions on junctures (Figure 1,2).

The results of dermatology and infectious disease consultations and skin biopsy revealed that the patient had SSSS. Staphylococcus aureus was observed in the blood culture of the patient taken at the time of admission to the intensive care unit. The patient was discharged on the $11^{\text {th }}$ day of hospitalization in the intensive care unit. 


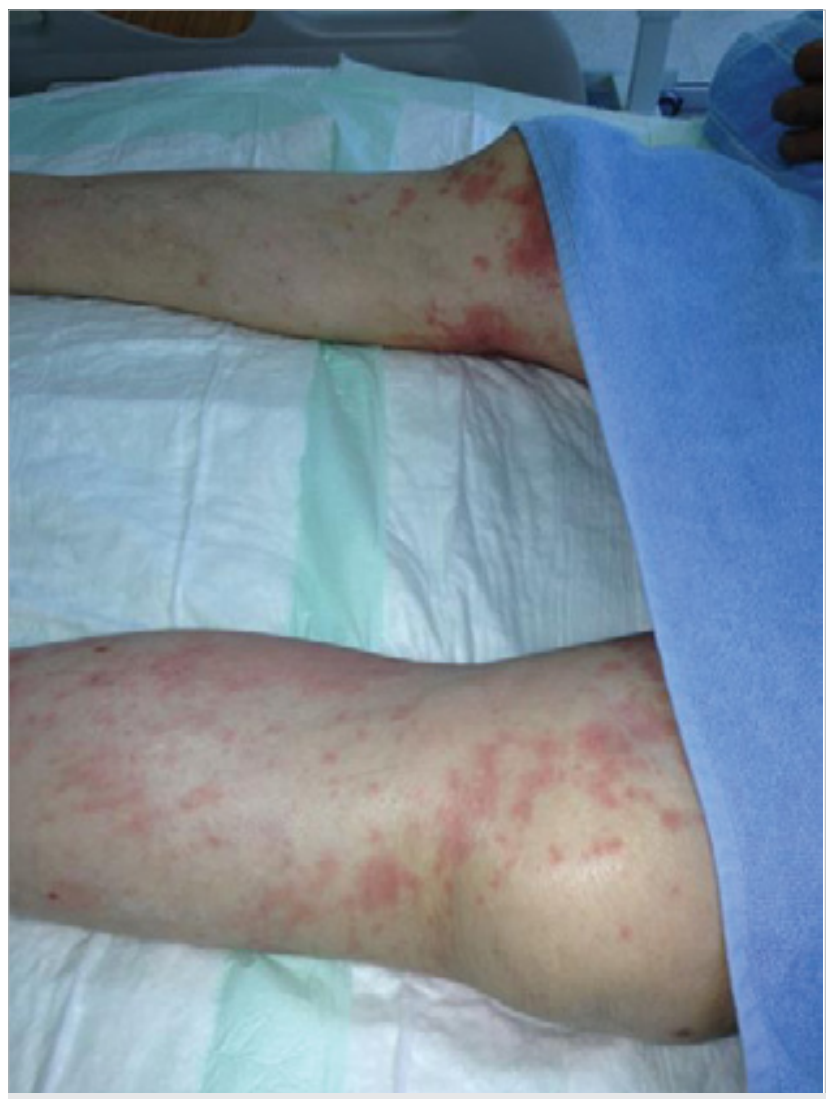

Figure 1. Skin eruptions on the interior surface of the leg

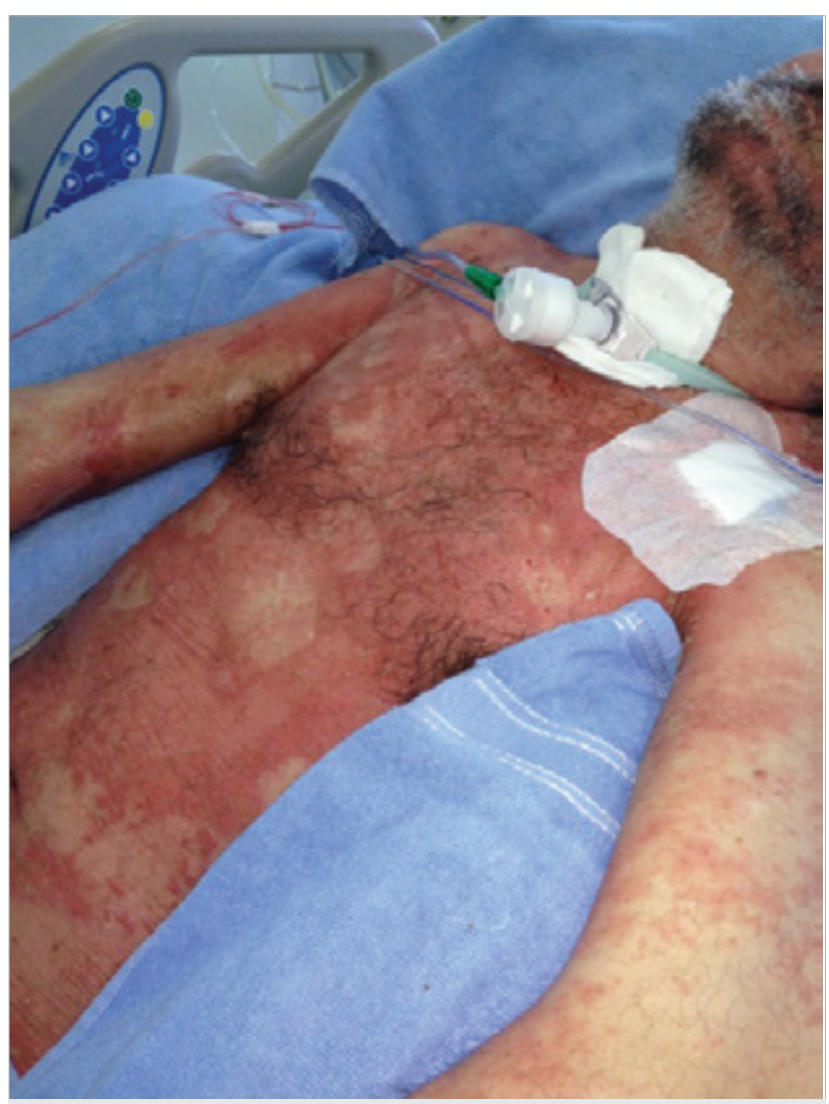

Figure 2. Skin eruptions on the front surface of the body

\section{Discussion}

SSSS can often be confused with Stevens-Johnson syndrome and toxic epidermal necrolysis (TEN). The mortality rates are $5 \%, 30 \%$, and between $40 \%$ and $60 \%$ in Stevens-Johnson syndrome, TEN, and SSSS, respectively (3-6). Diagnosis is established clinically, but the most important parameter for confirmation is skin biopsy. The production of microorganisms from the skin and blood cultures does not provide significant contribution to diagnosis. Antistaphylococcal therapy must be initiated immediately, and body temperature normalization, fluid balance, and regulation of nutrition must be provided. Combined therapies including gram-negative pathogens are inevitable. Although systemic glucocorticoids are preferred for skin eruptions caused by TEN, they are contraindicated for SSSS. Therefore, differential diagnosis is very important. Erythematous bullae with positive Nikolsky's sign are also seen in TEN. In addition, mucosal lesions definitely coexist. The absence of mucosal lesions in SSSS can be helpful in differential analysis (5).

In the literature, there are also some studies suggesting intravenous immune globulin (IVIG) therapy (4-5). Kato et al. (7) could not get a response to 3-day IVIG therapy in an adult patient in their case report, and they were successful when they used the plasma exchange method. If the patient is female, SSSS can occur as a part of toxic shock syndrome (5).

\section{Conclusion}

In conclusion, every skin eruption encountered in the intensive care unit should not be considered as a drug reaction, and consultation should be requested from related medical branches. Although SSSS is generally reported in pediatric cases, it can rarely be seen in adults with immunodeficiency $(3,7)$. The mortality rate regresses from $10 \%$ to $5 \%$, with appropriate and rapid treatment in pediatric intensive care unit; however, this rate decreases from $63 \%$ to $40 \%$ in adults (6).

Informed Consent: The authors state that, informed consent is taken from the patient's relative.

Peer-review: Externally peer-reviewed.

Author Contributions: Concept - S.Ü.Z., Z.S.; Design - S.Ü.Z., H.U.; Supervision - K.İ., S.Ü.Z.; Funding - S.Ü.Z., S.A.; Materials - H.U., S.A.; Data Collection and/or Processing - K.I.., S.Ü.Z.; Analysis and/or Interpretation - Z.S., K.İ.; Literature Review - S.A., S.Ü.Z.; Writer - S.Ü.Z, H.U.; Critical Review - Z.S., K.I.

Conflict of Interest: The authors declared no conflict of interest.

Financial Disclosure: The authors declared that this study has received no financial support.

\section{References}

1. Yaylı S, Sık görülen bakteriyal deri enfeksiyonları. Türkderm 2011, 45: 104-8. [CrossRef] 
2. Ladhani S, Garbash M. Staphylococal infectionsin children: rational drug treapy recommendations. Pediatr Drugs 2005; 7: 77-102. [CrossRef]

3. KoufakisT, Gabranis I, Karanikas K. Staphylococcal scalded skin syndrome in an adult, immunocompetent patient. Braz J Infect Dis 2015; 19: 228-9. [CrossRef]

4. Kapoor V, Travadi J, Braye S. Staphylocacal scalded skin syndrome in an exteremely premature neonate: a case report with a brief rewiev of litaratüre. J Peadiatr Child Health 2008; 44: 374-6. [CrossRef]
5. Scheinplug K, Schalk E, Mohren M. Staphylococal scalded skin syndrome in an adult patient with T- lymphoblastic non hodgkin's lymphoma. Onkologie 2008; 31: 616-9. [CrossRef]

6. Handler MZ, Schwardtz RA. Staphyloccal scalded skin syndrome: diagnosis and managenent in children and adults. J Eur Acad Dermatol Venerol 2014; 28: 1418-23. [CrossRef]

7. Kato T, Fujimoto N, Nakanishi G, Tsujita Y, Matsumura K, Eguchi $\mathrm{Y}$, et al. Adult staphylococcal scalded skin synrome successfully treated with plasma exchange. Acta Derm Venereol 2015; 95: 612-3. [CrossRef] 